\title{
'An altered view regarding the relationship between dreams and reality': Magic, politics and the comics medium in Alan Moore and Jacen Burrow's Providence
}

Matthew J. A. Green, University of Nottingham

\begin{abstract}
Alan Moore reports that through researching Providence he 'became more fully acquainted with academic literary criticism' and the extensive evidence of research throughout the series supports this claim. In this article, I argue that Providence uses the comics form to assert the value of humanities research, and of the arts more broadly, and to educate its audience in reading and research practices (some of which are more providential than others). My focus is on the relationships between imagination and the historical realities of readers; while the latter are not detailed at length, the discussion does map onto the real world of Brexit, the aftermath of the 2016 US Presidential election and austerity politics because Moore's underlying premise is that it is possible to trace the origins of our contemporary moment through the societal anxieties encoded in Lovecraft's fiction. The analysis combines key concepts from adaptation studies with the theoretical model of the comics system proposed by Thierry Groensteen; moreover, it both draws upon and extends Brian McHale's work on metafiction to suggest ways of extending Groensteen's model in order to better understand the way in which Providence uses the comics medium to put into practice his hopes concerning the world-altering potential of art and scholarship.
\end{abstract}

\section{Keywords}

Alan Moore

H. P. Lovecraft

adaptation studies and comics studies

literature and politics

literature and history

postmodernism 
In the times that we are moving through at present, with our leaders shameless and entirely unapologetic in their greed and callousness, with our environment teetering on the brink of finding out whether there's Life on Venus, with unanticipated new monstrosities arising from our complex global situation, surely it's time we realised that the culture imposed upon us from above is toxic to us. Surely it's time we grabbed the wheel and made some culture of [our] own, that says the things we want to say, that is exhilarating where the world is wretched, kind and fair where the world is tyrannical and drop dead gorgeous where the world is ugly. (Moore 2016: 7)

In H. P. Lovecraft's tales, we are afforded an oblique and yet unsettlingly perceptive view into the haunted origins of the fraught modern world and its attendant mind-set that we presently inhabit. Coded in an alphabet of monsters, Lovecraft's writings offer a potential key to understanding our current dilemma, although crucial to this is that they are understood in the full context of the place and times from which they blossomed. (Moore 2014: xiii)

Providence, written by Alan Moore and illustrated by Jacen Burrows, is the third part of an intersecting narrative set in an alternate reality that draws heavily on the fiction and biography of $\mathrm{H}$. P. Lovecraft. The previous two installments include a four-issue comics series - Neonomicon (Moore and Burrows 2011) - and a short story, 'The Courtyard' - later adapted into comics (Moore et al. 2009) - texts that draw on Lovecraft to discuss the darker side of the imagination's influence on the material world. These earlier texts follow an FBI investigation into a series of murders linked by the peculiar mutilation of the victim's bodies and by the fact that they are committed under the influence of Aklo, a language that the investigating agent, Aldo Sax, initially believes is a new 
street drug being sold by the enigmatic Johnny Carcosa. Neonomicon resumes the story with FBI Director Carl Perlman assigning two new agents to the case, Merril Brears and Gordon Lamper, who discover that elements from Lovecraft's mythos have begun contaminating their reality. The first ten issues of Providence function as a prequel, detailing a fictionalized account of the origins of Lovecraft's most enduring tales in conversations with the fictitious protagonist, Robert Black, an analogue of Lovecraft's fellow writer, Robert Bloch. Issue 11 fills in the gaps between the prequel and the previous texts, while Issue 12 depicts an apocalypse as witnessed by characters from across all three texts. Like Black/Bloch many of these characters correspond to real people, some of whom (like Black/Bloch) also have surrogates in Lovecraft's fiction, and the diegesis itself bears an uncanny relationship not only to the storyworlds of Lovecraft's tales but also to our world. A close examination of Providence therefore allows for an exploration of how the series encodes Moore's belief that culture - generated through a combination of desire and imagination - is fundamentally bound together with the world of material relations. This encoding is enhanced by the Gothic qualities of the narrative. Moreover, it yields new insights into the relationship between Moore's views on the political dimension of magic and the value of humanities research, whilst at the same time suggesting ways of combining comics studies and adaptation studies to better model the borderland state between real and fictional worlds.

\section{Apocalyptic research}

The creeping horror that powers most of Lovecraft's weird tales is generated by means of a cataclysmic revelation, the transmission of some terrible knowledge that spawns an apocalyptic transformation in the person who receives it and, often, in the wider world. Drawing on the longstanding motif of the perilous book, evident in the works of writers such as Edgar Allan Poe and Robert Chambers, Lovecraft distills cultural anxieties of the dangers of occult or otherwise illicit texts into his fictional Necronomicon, 'An imaginary volume that generated several real ones' (Moore and Burrows 2017: 1, original emphasis). A small number of these texts purport to be the 'real' Necronomicon and many more invoke this book in broader interweavings of the scholarly 
and/or the creative (Harms and Gonce 2003). In terms of their cultural effects, however, Providence follows Neonomicon in suggesting that historical accuracy matters less here than the structures of belief that such texts engender (Green 2013: 254-45, 266-67). Providence presents an extended meditation on the material potency of the text both through the numerous visual and verbal representations of books and pamphlets, and by embedding the motif of textuality at a structural level within the plot, the use of framing and the overall book design.

The first page of Issue 1 establishes the default page layout of the series: a stack of four horizontal panels each spanning the width of the page. These four opening panels depict a letter written in Robert Black's hand to Jonathan Russell, with the first panel occupied entirely by the first seven lines of the missive (our view ends mid-sentence):

Dear Jonathan, April 12, 1919

Well, what a night! I could have listened to you read from Huysmans forever. You seemed to break through the mere words to the reality lying beyond them. As for afterwards (and you know what I mean, you naughty boy), it was the most wonderful fun yet. You were like a wild animal and [...]. (Moore and Burrows 2015a: 1)

As we move down the page, our perspective zooms out to show Jonathan tearing the manuscript in two and dropping the torn leaves into the stream in Bryant Park, New York. This gradual outward movement is paced to track the tearing of the letter such that the park and city are slowly revealed, framed across panels two and three by an inverted triangle as the rip widens. We are thus provided with a visual parallel to the description of Jonathan's pre-coital, textual breakthrough, although the action in the park represents the dark double of that earlier performance: Jonathan destroys the letter because Robert has ended their relationship over fears of its discovery and he will soon end his life in the lethal chamber sited nearby in this version of Bryant Park.

The book design for each issue, meanwhile, draws attention to the materiality of textual history, alludes to the archival work undertaken in the production of the series and reflects on the 
effect that such research can have on the wider world. Spread across the inside front and back covers, we find a period map of Providence that adds an air of historical authenticity to the series at the same time as foregrounding the importance of symbol and convention in the representation of time and space. The landscape depicted by Burrows within the panels is at once more realistic and less real than the map's abstract translation of the real streets, roads and geographical features of Providence as it existed in our world at the outset of the twentieth century. The plot is orientated around textually based research: Black journeys deep into the New England landscape of Lovecraft's fiction collecting material for a novel about a hidden network of occultists and the subterranean dreamlife of America, a work that would allow him to discuss covertly the hidden world of gay men living in a homophobic world (Moore and Burrows 2015a: 32). In terms of his work as a researcher and writer - travelling to libraries, archives and other document repositories Black becomes a surrogate for Moore, whose extensive research for this series encompassed the consultation of primary sources, textual criticism and critical theory. This research activity is announced on the issue back covers, each of which presents a quotation from, variously, Lovecraft's stories, his letters and Rheinhart Kleiner's memoir, 'Bards and Bibliophiles'. These quotations establish an archival atmosphere that is sustained throughout the comics by the inclusion of faux manuscripts and pamphlets in the appendices of Issues 1-10, and by the numerous books and photographs - both fictional and real - that are shown within the storyworld itself.

The cover quotations themselves are translated into the storyworld in ways that paradoxically reinforce a sense of authenticity and coherence within the diegesis, while simultaneously drawing attention to the fact that what we have in front of us is packaged as fiction rather than fact. For example, the quotation from Kleiner, printed on the back cover of Issue 2 (Moore and Burrows 2015b), describes ‘an ancient Dutch cemetery in Flatbush' and recounts, 'Lovecraft was delighted with the "Hier Lydt" [...] still plainly discernible on the pieces of scaling red slate'; Burrows accordingly draws Black visiting the Flatbush cemetery in a detailed series of panels that include a gravestone of the sort that Kleiner describes (Moore and Burrows 2015b: 8). Black enters the graveyard to meet Suydam, a pre-existing character transplanted from Lovecraft's 
story, 'The Horror at Red Hook', to which the issue's title, 'The Hook', alludes, offering a rich blending of the fictional and the historical.

Notably, Black is represented not only as a researcher and writer but also an amateur critic. In Issue 7, 'The Picture', the narrative is structured around the Boston police strike of 1919 and Lovecraft's story, 'Pickman's Model', in which the supernatural elements found in the paintings of Richard Upton Pickman are revealed to be based on real rather than imaginary monsters. The analogue for Pickman in Providence is Ronald Underwood Pitman, who shows Black his work. Viewing a painting of monsters devouring men and women on a subway platform, Black reads the picture as a political allegory representing 'the anger of the downtrodden lower classes [...] Erupting into violence, like with the police strike' (Moore and Burrows 2016a: 13, original emphasis). This assessment of the supernatural elements in Pitman's work echoes Moore's own assessment of Lovecraft's fiction as an imaginative embodiment of cultural fears and conflicts. Despite the fact that Pitman knows that in a very material sense the monsters are real, he qualifies but does not reject Black's reading: 'my work is related to dreams. And so is, uhm, so is politics' (Moore and Burrows 2016a, original emphasis). Thus, political and economic explanations of violence are shown as encompassed by, rather than opposed to, a broader understanding of the political imaginary that corresponds with Moore's own views on magic: 'as a magician [...] you are criticising reality $[\ldots]$ the very bedrock that all of our concepts of politics and economy and philosophy are standing upon' (Moore and Green 2011).

Moore's equation of art with magic - 'By understanding art as magic [...] we thus return to the magician his or her original shamanic powers and social import' (2010) - is relatively well known, but Providence takes this a step further extending the overlapping fields of the artistic and the magical to include works of interpretation and research that are depicted as fundamental to the transmission of a cultural inheritance capable of bringing about change on a global scale. The research and reflections included in Black's commonplace book and the tentative forays into literary criticism revealed in his conversations with Lovecraft (whom he meets in Issue 8) are represented as indispensable for the development of the Lovecraftean mythos that will bring on the 
apocalypse. Underscoring the relevance of literary scholarship not just to the series but also to the potency accorded to fiction and art more generally, the renowned Lovecraft scholar, S. T. Joshi, is afforded a place as a witness to the apocalypse. Moore may be taking his cue from Lovecraft himself here - after all, several tales include university professors as key actors - but there is a richness to Joshi's narrative and meta-narrative functions here that is absent from Lovecraft's characterizations of Miskatonic staff. In the face of trans-dimensional beings, alien technologies and ontological uncertainties (Moore and Burrows 2017: 19-20, 29-31), Joshi's literary knowledge is accorded an explanatory force that leads Agent Brears to describe him as the 'last remaining scientist' (Moore and Burrows 2017: 31).

Joshi's very appearance in the story exemplifies the possibility of a self-reflexive criticism that fully immerses itself into its subject, whilst also reaching beyond the text to a wider reality. He becomes an actor in the narrative, but he also exercises a meta-narrative function bridging the gap between the diegesis and our world. Within the storyworld, Joshi demonstrates an embrace of the dialogic and an openness to alterity that allows him to develop with his circumstances - 'I-I'm starting to assimilate this. New York already seems like an impossible Dunsany Fantasy' (Moore and Burrows 2017: 27, original emphasis). Yet, he also retains a higher-level awareness, able to perceive and question his position within a larger narrative: 'What place does this world have for FBI agents or literary scholars?' (Moore and Burrows 2017: 29, original emphasis).

While this line has added resonance in view of Donald Trump's decision to remove James Comey as Director of the FBI, Providence ultimately suggests that such agencies are poorly equipped to deal with the cultural forces responsible for the disfiguration of the political landscape. Perlman takes a forensic interest in scholarly work, but as an agent of federal law enforcement/surveillance his role is to maintain the status quo and he ultimately shows little respect for material texts. The final four-panel page of the series mirrors the first page of Issue 1, but instead of the letter to Jonathan the manuscript consists of the pages from Black's commonplace book, and it is Perlman who tears them asunder, revealing the alien landscape of post-apocalyptic America. On one level, this is an act of censorship - Perlman destroys the journal on the grounds 
that it inspired Lovecraft's tales - but as a repetition of the opening scene it is also revealed as an act of despair.

\section{Metacomics and adaptation}

When contrasted with Promethea (Moore and Williams 2004), Moore's other sustained meditation (in comics form) on the relationship between writing and apocalypse, Providence and its precursors ('The Courtyard' and Neonomicon) appear very pessimistic. Promethea concentrates on an internal apocalypse that positively alters the self's comportment with the world, a change that is offered to all, but not imposed:

It's not even like there aren't still wars and murders and rapes.

Everybody had the revelation, but not everybody understood it, or took any notice of it. Though maybe enough people did. Things are changing. (Moore and Williams 2004: 17, original emphasis)

Whereas the physical landscape in Promethea remains largely unaltered, the characters in Providence find the world that they inhabit transformed into something inimical and dreadful, an environment that in comparison with commonly accepted understandings of reality has erupted into madness. Johnny Carcosa, the dealer in Aklo, appears at the apocalypse with the assertion that 'Exithtenth ith a thingle thtep from the thublime./ You thee how eathily it all thlips away? How it thubmith before a thrtonger ficthion?' (Moore and Burrows 2017: 21-22, original emphasis). ${ }^{1}$ Subsequently, Brears suggests that perhaps the world has 'always been Yuggoth', the alien planet Lovecraft introduces in 'Whisperer in the Darkness' (Moore and Burrows 2017: 28, original emphasis), with Joshi developing this proposition further: 'And human reality has only ever been a fragile construct that we briefly imposed upon the fundamental chaos of existence' (Moore and Burrows 2017: 29, original emphasis). Taken together, these comments suggest not that the world depicted across Lovecraft's mythos is truer but that it is stronger, a view that likely reflects a sober 
appraisal of the resurgence in the present of xenophobic discourses descended from those encoded in Lovecraft's tales. But if the apocalypse in Providence feels like it has been imposed from without, the series also provides some of the intellectual resources required to resist such imposition. Through the use of metatextuality and adaptation, Providence structurally embodies the very intercourse between the fictional and the real that the narrative describes; moreover, the identification of approaches to texts that lack the potency required to counteract such oppressive impositions combined with Moore's broader views on the relationship between magic and politics can be used to outline more concrete modes of resistance than those suggested in Promethea.

As a number of scholars have noted, the comics medium encourages a metafictional response in readers and creators, thanks to elements such as its multimodality, linear and non-linear modes of relation, and the hand-drawn feel of images and/or letters (Atkinson 2010; Cook 2012, 2017; Joseph 2012). Moreover, Moore's prevalent use of self-referentiality has been noted by scholars (Di Liddo 2009; Kidder 2010) and its specific links to his views on magic and apocalypse are well established (Green 2011, 2012, 2013). In Providence, Moore and Burrows' use the comics medium to open a number of metatextual fissures throughout the presentation of the narrative. The most fundamental structural element that achieves this effect is the use of panelling to affect the comic's rhythm. As Groensteen (2013: 138) notes 'beat [...] is closely dependent on [...] the arrangement of panel frames' and 'when the layout is regular, so is the beat'. Moore's use of the four-panel horizontal grid thus establishes a simple rhythm that is regularly - but in most instances minimally - interrupted by panels that are differently sized or that are orientated vertically rather than horizontally. Given that a regular layout 'possesses the ultimate virtue of handling the possibility of sudden and spectacular ruptures from the initially given norm' (Groensteen 2007: 97), it makes sense that panel variation in Providence often serves to cue metatextual effects. Thus, for example, the second page of each issue consists of a full-page panel, which encourages the readers to pause in their pursuit of the narrative and to contemplate the scene in which the action unfolds, an effect that both distances us from the story whilst drawing us into the storyworld itself, paradoxically interrupting the narrative flow by more fully immersing us in Burrows' visual 
representation of the scene. Elsewhere, variations in panelling are used to highlight transitions from one mode of reality to another. Thus, the first shift from horizontal to vertical panels corresponds with the point in the plot when Black first finds himself in the subterranean dreamworld (Moore and Burrows 2015b: 16-23). Unsurprisingly, when the series reaches its apocalyptic climax in Issue 12, during which the real world becomes thoroughly transfigured in accordance with Lovecraft's mythos, we find the regular structure interrupted on more occasions than in any other issue. ${ }^{2}$ An increased number of larger panels (ranging from half- to full-page panels) interrupts the reading flow and draws attention to the apocalyptic events, including the appearance of the monstrous Azathoth and Shub-Niggurath (Moore and Burrows 2017: 18, 30). Similarly, the compressed grid on page 24, composed of eight rather than four panels, juxtapose close-ups of Brears giving birth to Cthulhu with the facial responses of those who are present for this event. Finally the use of vertical panels on pages 6 and 7 emphasizes the environmental transformation of the landscape. There are three equally sized panels spread across each page and, taken together, they suggest a single cityscape in which the panel borders maintain a regular beat that aligns with the moment-to-moment transitions between panels; however, in the movement across the page divide (i.e. in the gutter between panels three and four), the city is suddenly transformed by alien flora and fauna, reinforcing the narrative's account of a disjunction between time and space: 'it's like those dreams where geography is compressed, and there's a little-known shortcut to everywhere' (Moore and Burrows 2017: 6, original emphasis). This movement from a pre- to post-apocalyptic landscape creates a sense of the uncanny by distorting the mimetic effect achieved by Burrows' use of a clear line and his incorporation of a high level of detail, which suggests extensive use of photo reference.

The juxtaposition of a world that feels familiar with an alien landscape drawn from Lovecraft's fiction allows us to understand Providence as a work of both adaptation and mimesis. The description of Providence as an adaptation is not unproblematic, but the series does fit within the definition proposed by Linda Hutcheon (2006: 33): 'a creative and interpretive transposition of a recognizable other work or works'. This definition is applicable at a global level, in which Moore and Burrows adapt Lovecraft's storyworld, and at the level of individual issues, each of which 
incorporates elements such as character, setting and plot from other fictional works, predominantly penned by Lovecraft. However, there is no single source as each issue draws on a range of material from fictional and non-fictional work, including primary and secondary sources relating to biography and geography.

Hutcheon (2006: 21) notes that audiences experience adaptations as having a “"palimpsestuous” intertextuality': ‘adaptations are obviously "multilaminated”; they are directly and openly connected to recognizable other works, and that connection is part of their formal identity, but also of what we might call their hermeneutic identity'. In other words, in order to be recognized as such, the adaptation must trigger a metatextual recognition that allows the audience to relate it to the adapted text or texts; however, this process depends on minimizing 'all the other intertextual parallels to the work the audience might make' (Hutcheon 2006). Visually and verbally, however, Providence does the opposite, amplifying this intertextuality, repeatedly drawing attention to the doubling effect of literary language and ambivalence identified by Julia Kristeva (1981: 68): 'the insertion of history (society) into a text and of this text into history'. Moore and Burrows' ostentatious display of this interpenetration of the history and the fictional not only reinforces the message of the text but also foregrounds the political potency of this connection by drawing attention to the way in which the process of world-building - both within the world of the story and the world of the reader - interweaves the imaginary with the material.

One of the key ways to visualize this overlap is through an examination of the way in which the adaptation of other worlds functions across the series. Referring to adaptations that are not tied specifically to the adaptation of a set plot, such as the Aladdin theme park ride at Disney World and the videogame adaptation of The Godfather, Hutcheon (2006: 14) comments: 'what gets adapted here is a heterocosm, literally an "other world" or cosmos, complete [...] with the stuff of a story settings, characters, events, and situations' (2006). Further, she notes that 'this world also has a particular kind of "truth-of-correspondence" - not to any "real world" but to the universe of a particular adapted text' (2006). The quotations printed on the back covers of Issues 10 and 11 excerpt world-building descriptions from Lovecraft's 'The Haunter of the Dark' and 'He', 
respectively, that form part of the heterocosm adapted in these issues (Moore and Burrows 2016d, 2016e). However, here the truth-of-correspondence is simultaneously related to both real and fictional worlds. Thus, Burrows' visual depictions of Saint John's Roman Catholic Church on Federal Hill, drawn on the cover and featuring significantly throughout Issue 8, establish a relationship with the quotation from 'The Haunter of the Dark' - 'of all the distant objects on Federal Hill, a certain huge, dark church most fascinated Blake' (Moore and Burrows 2016d) - and to the real place and photographic renditions of it (as available, for instance, on Google maps). Similarly, Issue 11 quotes the heavily mythologizing description of New York contained in Lovecraft's 'He':

I had looked for poignant wonder and inspiration in the teeming labyrinths of ancient streets that twist endlessly [...] and in the Cyclopean modern towers and pinnacles that rise blackly Babylonian under waning moons, I had found instead only a sense of horror and oppression which threatened to master, paralyse, and annihilate me. (Moore and Burrows 2016e)

These descriptions suggest a relationship between fictional worlds and actual geography in which the mimetic aspect of art becomes bound together with the adaptation of a fictional heterocosm, which itself has a mimetic function even if the reflection is deliberately distorted.

In his study of metatextuality in postmodernist fiction, Brian McHale (1987: 28) remarks upon the mutual dependence of the mimetic view of art and the notion that fiction creates an alternate world: 'a mimetic relation is one of similarity, not identity, and similarity implies difference - the difference between [...] the real world and the fictional heterocosm'. The intersection in Providence of the storyworld with historical representations of geography neatly illustrates McHale's (1987: 28) observation of 'a certain kind of overlap or interpenetration between the heterocosm and the real', one that 'spoils the simple geometry of the mirror held up to nature' (McHale 1987: 29). From Issue 2 onward, this overlapping of the real and the unreal is inflected by the effacement of the distinction between the worlds of dream and those of imagination such that 
the pages of Providence make manifest the deviant ontology attributed to Khālid Ibn Yazīd's imaginary grimoire in the appendix of that issue (Moore and Burrows 2015b: 31): 'there are suggestive passages referring to an altered view regarding the relationship between dreams and reality, with implications of a vastly different version of terrestrial history arising from this notion'.

The relationship between dreaming and waking realities is indexed directly on the back cover of Issue 12, which takes its quotation from 'Beyond the Wall of Sleep' (Moore and Burrows 2017):

We may guess that in dreams, life, matter, and vitality, as the earth knows such things are not necessarily constant; and that time and space do not exist as our waking selves comprehend them. Sometimes I believe that this less material life is our truer life, and that our vain presence in the terraqueous globe is itself the secondary or merely virtual phenomenon.

While the apocalypse is described in terms of a shift from one ontological pole to another - 'dreams and our world are two extremes of a bi-polar reality, that can flip from one state to the other' (Moore and Burrows 2017: 5) - images and plot elements from 'Beyond the Wall of Sleep' also feature in Issue 8, which expends considerable time charting Black's foray into the dreamlands, led by Randall Carver, an analogue for Lovecraft's Randolph Carter. Here, the flipping between these two poles is embedded within the page layout itself. Thus, the regular four-panel grid that runs across pages 4-7 juxtaposes two different worlds as the panels alternate between depicting Black and Carver having tea in Carver's house and showing them in diverse historical and fictional settings. In addition to juxtaposing different places, Moore also sets up three different rhythms in these pages, achieving the same effects as Groensteen (2013: 154) has identified in certain 'remarkable' pages from Watchmen (Moore and Gibbons 1986-87): 
the ternary rhythm of the strip, the binary rhythm of the A-B alternation, and the rhythm of the text, at once regular in that it sits atop two series of images with no interruption - and irregular, in view of the varying length of the lines of dialogue.

In fact, Providence takes this effect further than Watchmen, for while it is possible to describe this alternation in binary terms - A-B-A-B - where A is the 'real' world internal to the diegesis and B is the dreamworld, the internal inconsistencies of the dreamworld as depicted across these four pages yield the more complex pattern of $A-B_{1}-A-B_{2}$ (page 4), $B_{3}-A-B_{3}-A$ (page 5), $B_{4}-A_{-}-B_{5}-A$ (page 6) and $\mathrm{B}_{6}-\mathrm{A}_{-} \mathrm{B}_{7}-\mathrm{A}$ (page 8). This pattern continues across pages 8 and 9 (although here with a move to a layout of three vertical panels per page) and is only broken on page 10 when the return of the horizontal panels underscores the dominance of a single narrative sequence (although it is the dream sequence and thus does not obey the same natural laws as the waking world).

McHale's reading of the third section of Thomas Pynchon's Gravity's Rainbow ('In the Zone') provides another perspective on the proliferation of heterocosms in Providence. Drawing on Foucault's (1970: xviii) description of the heterotopic space, 'in which fragments of a large number of possible orders glitter separately in the dimension, without law or geometry', McHale (1987: 45) describes the 'paradigmatic [...] heterotopian space' in which 'a large number of fragmentary possible worlds coexist in an impossible space'. McHale (1987: 56) argues that fictional worlds can properly be described as heterotopic if they annex one or more different types of space: the physical space of the page, the conceptual space of language and intertextual space. Setting the question of intertextual space aside for the moment, it is clear that the comics medium specifically conjoins the fictional world of the narrative to the physical dimensions of the page (or screen) and likewise supplements the spatialization resulting from the sign's separation into the signifier and the signified with the introduction of three different signifying codes, the verbal, the visual and the verbal-visual. In this respect, all comics can be described properly as heterotopic and, moreover, the comics medium adds a fourth type of space: the temporal. As Julia Round (2014: 60) notes, 'The architecture of the comics page is [...] a haunted one, which literalizes the "fourth dimension" by 
realizing time as space: offering a static, spatial layout of images that rely on processes of braiding and gridding'. Thus, the comics structure itself is subject to the same sorts of haunting as those discussed and depicted throughout Providence, a fact that reveals a further metatextual dimension to the description of Khālid's grimoire: 'here we find ruminations on eternity as an unchanging solid, the idea of time itself demoted from a matter of duration to one of mere distance' (Moore and Burrows 2015b: 31).

Intertextual space requires particular attention here not only because the visual register of comics often allows us literally to see such connections but also because it encourages a reconsideration of braiding, one of the medium's fundamental processes. McHale (1987: 56-57) reports that 'an intertextual space is constituted whenever we recognize the relations among two or more texts, or between specific texts and larger categories such as genre, school, period'. While he does not discuss adaptation as such, he does argue that 'there are a number of ways of foregrounding this intertextual space and integrating it in the text's structure, but none is more effective than the device of "borrowing" a character from another text' (McHale 1987: 57). Such borrowings are prevalent throughout Providence and they reach their peak in Issues 11 and 12 when the different narrative fragments present an assemblage of characters from Lovecraft's tales who feature in previous issues, historical figures involved in the production and popularization of Lovecraft's works and mythos (such as Joshi), characters from 'The Courtyard' and Neonomicon (Carcosa, Sax, Perlman and Brears) and a handful of Lovecraftean deities (Azathoth, Cthulhu and Shub-Niggurath). Invariably, these figures become the subject of braiding, which, as Groensteen (2007: 151) defines it, 'is generally founded on the remarkable resurgence of an iconic motif (or of a plastic quality)'. For our purposes, we can confine ourselves to the iconicity that emerges through Burrows' visual representations of these characters, allowing us to recognize them as they appear across different panels (often non-sequential) of single issues and of the series as a whole. For example, when Shadrach Annesley appears at the apocalypse in Issue 12 (Moore and Burrows 2017: 14), his identity is signalled immediately through visual cues (clothes, body-shape and facial features) that refer us back to Issue 3 (Moore and Burrows 2015c: 8-9) and is then confirmed in the 
dialogue. Similarly, we have an example of what can properly be called 'intertextual braiding' when the characters from 'The Courtyard' and Neonomicon (Perlman, Sax and Brears) appear in Issue 11 and whenever the comic introduces characters from Lovecraft's stories, translating verbal descriptions into a visual depiction (as with the incorporation of Elspeth Wade, drawn from Lovecraft's 'The Thing on the Doorstep'; Moore and Burrows: 2015e: 1-7).

Examples of braiding across texts by different authors and across different media already suggest the need to recognize that the iconic solidarity of comics stretches beyond the covers of individual publications. Matters become more complicated, however, with the representation of historical figures such as Lovecraft and Joshi, whose appearance demands an additional extension in the way in which we conceive of the systematicity of comics. The detailed exploration of what it means to think of comics as a network is one of the key contributions of Groensteen's work and he describes the comic book (or album) in the following terms:

within the paged multiframe that constitutes a complete comic, every panel exists, potentially if not actually, in relation with each of the others. This totality, where the physical form is generally, according to French editorial norms, that of an album, responds to a model of organization that is not that of the strip nor that of the chain, but that of the network. (2007: 146, original emphasis)

If, as Groensteen (2007: 158) suggests, 'braiding thus manifests into consciousness the notion that the panels of a comic constitute a network', then the appearance of historical figures necessarily extends this system to include extratextual materials such as photographs, portraits and, potentially, even personal encounters. The inclusion of paratextual material (the map, commonplace book and occasional pamphlets) between the covers of each issue further encourages such a reconsideration of the limits of the multi-page hyperframe, as does the inclusion of fictional photographs within individual frames and on issue covers (e.g. Moore and Burrows 2015d: 21, 2016c). 
Similarly, the depiction of the books spread out across Perlman's desk in the first three panels of Issue 12, and their position above the fourth panel showing Black's commonplace book resting on Perlman's lap (Moore and Burrows 2017: 1), uncovers an intercourse between the fictional and the real at the heart of intertextuality itself. 'It has become commonplace', McHale (1987: 56) writes, 'to picture literature as a field or, better, a network whose nodes are the actual texts of literature'; Issue 12, however, alerts us to the presence of the imaginary at the heart of the 'actual'. Whereas, for example, Burrows' drawings of H.P. Lovecraft: A Critical Study (Burleson 1983 ) and Lovecraft at Last (Lovecraft and Conover 1975) are signifiers referring to physical objects that exist on the same material plane as the book in which these pictures are contained, the drawing of the commonplace book, depicted on Perlman's lap, only exists within the fictional world.

Within the covers of an individual comic book, album or issue, the associative logic of braiding supplements the 'syntagmatic logic of the sequence' such that 'through the bias of a telearthrology, images that the breakdown holds at a distance [...] are suddenly revealed as communicating closely, in debt to one another' (Groensteen 2007: 158). What the above analysis suggests is that this tele-arthrology remains operative beyond the borders of the book, ${ }^{3}$ closing the gap not only between literary texts but across the entire domain of culture, asserting the place of fiction as part of the frame through which we organize and interpret the multitude of lived experience. Providence is not unique in this respect, but in its plot and throughout its structure, the series draws serious attention to the interpenetration of the fictional and the non-fictional across the intertextual network. Moreover, by highlighting the way in which the imaginary and the real interact across this network, Providence reveals that intertextual space is not simply one means of generating a heterotopic effect, but rather that 'heterotopia' names the very condition, or precondition, of intertextuality itself.

\section{From spectral reading to Peasants with Pens}


As he heads towards the climax of Providence's apocalypse, Perlman reflects on the relationship between the dramatic transformation of the external landscape and the psychological changes that he perceives in himself:

This feels more dreamlike all the time. There's that acceptance, like everything that's happening is somehow normal.

The world inside us [...] that's changing too. Maybe that's the only world that's changing. (Moore and Burrows 2017: 7, original emphasis)

As the narrative develops, it becomes clear that the acceptance of this 'new normal' is ethically problematic, a point registered in Perlman's horrified expression in the third panel of page 11 and emphasized for the reader when it is revealed that he has just opened the door onto a room full of dancing college students who have been beheaded, had their chests cut open and their hands cut off (Moore and Burrows 2017: 12). It is, however, possible to challenge a dominant narrative (and here we can read Carcosa's fiction as a surrogate for the 'monstrosities' that Moore (2016: 7) attributes to our current geopolitical situation) by working with an awareness of the convergence of the fictional and the real within world-building discourses: 'When you think about it they're like spores. The life of another world, finding purchase in a human mind', we read in the first panel from Issue 12 (Moore 2016: 1, original emphasis), words that evoke not only Lovecraft's sonnet cycle, Fungi from Yuggoth, but also Moore's Yuggoth Cultures (Moore et al. 2007). ${ }^{4}$ This selfreflexive moment suggests that such contamination is neither pre-determined nor automatically antithetical to human values, an interpretation strengthened by Perlman's subsequent comment: 'Any effective narrative acts as a contagion' (Moore 2016, original emphasis). In fact, the permeability of textual and psychological worlds speaks to a displacement of the frontier between the public and private that Jacques Derrida (1994: 50-51, original emphasis) links to teletechnologies: 
If this important frontier is being displaced, it is because the medium in which it is instituted, namely, the medium of the media themselves (news, the press, telecommunications, techno-tele-discursivity, techno-tele-iconicity, that which in general assures and determines the spacing of public space, the very possibility of the res publica and the phenomenality of the political), this element itself is neither living nor dead, present nor absent: it spectralizes. It does not belong to ontology, to the discourse on the Being of beings, or to the essence of life or death. It requires, then, what we call [...] hauntology.

Although it may be accelerating, this process of spectralization is at least as old as language itself and emanates from what Moore (Moore and Green 2016) describes as 'the twilight area' through which 'all culture emerges into being'.

Derrida's use of the spectre (a figure of that which is at once living and dead, embodied and disembodied) as a means of understanding cultural inheritance is similarly helpful in thinking through Moore's approach to Lovecraft: 'one never inherits without coming to terms with some specter, and therefore with more than one specter' (1994: 21). Providence arguably treats Lovecraft as a spectre, entering into dialogue with a cultural antecedent who is both an ally and an opponent. For, if Lovecraft's stories give shape to the fears and opinions of 'those of the white, middle-class, heterosexual, Protestant-descended males who were most threatened by the shifting power relationships and values of the modern world' (Moore 2014: xiii), Providence resurrects Lovecraft and his monstrous codes with a view to understanding - and commenting critically upon - the darker side of the cultural and political legacies occasioned by the rise to ascendancy of the US over the past century. As Matthew Kirshenblatt (2017) notes, just as Moore considers Lovecraft as 'sensitive enough to tap into the collective fears underlying American culture and society', so too

it is eerie, looking at Brexit and North America now, and comparing them to the events in Providence: to the rise of the then-governor Coolidge during the police union strike in his State, to the rise of extremism in Europe and America, and the rise of darkness in general. 
In the pre-publication publicity for Providence, meanwhile, Moore (Moore and Andrade 2015, back cover) describes the series as 'an attempt to marry Lovecraft's history with a mosaic of his fictions, setting the man and his monsters in a persuasively real America during the pivotal year of 1919'. Moore's further elucidation - 'this is the story of the birth of modern America, and the birth of modern American terror' (Moore and Andrade 2015) - relates Providence to the concern with haunting noted by Christopher Murray (2013: 215-16), who describes Moore as a 'resurrection man' who 'is interested in the mutability of time and space, and the way the past haunts the present'.

The connection between the haunted architecture of the comics medium and Derrida's work on spectralization was first mooted by Round, whose work speaks to the final concern of this article, namely how to understand the socio-political interventions of a text such as Providence. Round (2014: 19) writes of a 'spectral criticism' that aims at deciphering haunted objects/texts and she describes the reader as a 'revenant' who 'alongside interpreting the diegesis [...] has an active role in putting together the paratextual material of the comic' (Round 2014: 106). Of particular relevance, she draws specific attention to Moore's work while also noting the way in which the textual object encodes a process of social exchange:

This is exploited by titles such as Alan Moore and Kevin O'Neill's The League of Extraordinary Gentlemen [...] which includes Victorian-style adverts, and classic texts such as Watchmen which include extracts from (fictional) biographies, other comics, news stories, psychiatric evaluation files and so forth as part of its diegesis. Even in more standard monthlies, a paratextual dialogue is created (historically this occurred through letters pages and so forth, a more up-to-date equivalent would be via online forums or Twitter), and creators write and publish titles whose narratives frequently look forward to both the next issue and their reception by the reading community. (Round 2014: 106-07) 
It is precisely the social dimensions of the text - both the way in which it solidifies a clear set of social relationships and the role played by the readerly community - that Robert Black overlooks to his peril in Providence (2017: 6, original emphasis): 'the Stella Sapiente's strategy was to get knowledge $[. .$.$] through to their redeemer through an equally important "herald"./ The Redeemer$ was Howard Phillips Lovecraft./ The Herald was Robert Black’. Specifically, Black fails to recognize the extent to which the archival material that he consults relates to an ongoing revolutionary programme and erroneously views himself as beyond the socio-textual networks that he is researching. This leads to a trenchant use of dramatic irony in Issue 6 (Moore and Burrows 2015f: 1) - here Black finally obtains access to Hali's Booke of the Wisdom of The Stars and fails to recognize himself in the proclamation that 'black is the messenger, and black is his path'.

Providence reasserts the cultural power embedded in fictional worlds and academic texts, extending Moore's views on the magic of writing into the field of scholarly practice at a time when the value of the arts and humanities is increasingly under attack (Preston 2015; Roussi 2017). Further it asserts the cultural importance of the archive, at a time when libraries are under serious threat from austerity programmes that Moore continues to vocally oppose (Redigolo 2017). The narrative itself offers few suggestions for how to counteract the 'Innsmouth Tide' (Moore and Burrows 2017: 31, original emphasis); however, Moore gives us enough pointers to make the connections that allow us to read Providence both as a meditation on the relationship between text and context, and also as a critical commentary exposing the cultural undercurrents responsible for the current transformation of the geopolitical landscape. A product of extensive research, critical reading and self-reflexive artistic practice, Providence demands an active mode of spectral reading capable of meeting the demands of heterotopic space, an interpretative endeavour that not only traces but acts upon the nodes connecting the fictional and the real. In short, it encourages us to become better readers, better teachers and better makers.

Terry Eagleton has defined the task of the critic as 'to participate in... the cultural emancipation of the masses', although he notes that this 'describes the task $[\ldots]$ in far more politically hopeful times than we're living through at present' (Eagleton and Beaumont 2009: 312). 
Beyond interventions as a public intellectual, Eagleton lists activities such as 'the organization of writers' workshops and popular theatre, the business of public design and architecture and so on' as good critical practices. All of this sounds surprisingly like the work undertaken by the UK Arts Labs in the 1970s and perhaps it is no surprise that Moore has recently become involved in reincarnating the Northampton Arts Lab, out of which his own early work emerged. Indeed, in an interview that formed part of the background research for this article (Moore and Green 2016), Moore moved from a detailed discussion of post-structuralist semiotics and self-referentiality to an enthusiastic account of his work with this grass-roots organization of creators. The tenor of this discussion clearly indicated that he did not conceive of these as necessarily separate activities.

Providence can, if we let it, operate both as a powerful model for cultural critique and an assertion of the power of work - creative and critical - in the arts and humanities. In order for it to function as such, though, scholarship must become a genuinely social (with a small 's') enterprise, involving a sharing of creative practice and reading strategies across different audiences. This is not necessarily a call to buy into a broader 'impact' agenda - and Moore would likely approve of Raymond Williams ([1980] 2005: 180) sense that "impact" like "consumer" is now habitually used by people to whom it ought to be repugnant'; that said, counter-cultural renovations must make use of opportunities wherever they can be found: 'stick an ad in the paper or a card in a newsagent's window or just get together with some similarly minded friends and see what happens' (Moore 2016: 7). If Providence provides the theory for such work, Peasants with Pens, an eclectic magazine put out by the Northampton Arts Lab, puts these into practice. Peasants with Pens and the Lab's associated activities - including their work with arts-emergency.org, local theatre performances, meetings and other happenings - provide some examples of work that draws on collective resources in an attempt to create a stronger fiction. If as readers we can learn the lessons encoded in a piece such as Providence, then as critics we ourselves need to move beyond - not abandon but transgress - the boundaries of academic publication.

\section{References}


In addition to the sources listed below, the following resource has proved invaluable in cataloguing the allusions and cross-references in Providence: Linton, Joe and Deri, Robert (2015-17), 'Facts in the case of Alan Moore's Providence: Annotations of H.P. Lovecraft comics', https://factsprovidence.wordpress.com/about/. Accessed 24 October 2017.

Atkinson, Paul (2010), 'The graphic novel as metafiction', Studies in Comics, 1:1, April, pp. 10725.

Attridge, Derek (2004), The Singularity of Literature, London: Routledge.

Burleson, Donald R. (1983), H.P. Lovecraft: A Critical Study, Westport, CT: Greenwood Press.

Cook, Roy T. (2012), 'Why comics are not films: Metacomics and medium-specific covnentions', in Aaron Meskin, and Roy T. Cook (eds), The Art of Comics: A Philosophical Approach, London: Blackwell, pp. 165-87.

(2017), 'Metacomics', in Frank Bramlett, Roy T. Cook and Aaron Meskin (eds), The Routledge Companion to Comics, London: Routledge, pp. 257-66.

Derrida, Jacques (1994), Specters of Marx (trans. Peggy Kamuf), London: Routledge.

Di Liddo, Annalisa (2009), Alan Moore: Comics as Performance, Fiction as Scalpel, Jackson, MI: University Press of Mississippi.

Eagleton, Terry and Beaumont, Matthew (2009), The Task of the Critic: Terry Eagleton in Dialogue, London: Verso. 
Foucault, Michel (1970), The Order of Things: An Archeology of the Human Sciences, New York: Pantheon.

Green, Matthew (2011), “'She Brings Apocalypse”: Sex, imagination and redemptive transgression in William Blake and the graphic novels of Alan Moore', Literature Compass, 8:10, pp. 73956.

(2012), “The end of the world. That's a bad thing right?”: Form and function from William Blake to Alan Moore', in Clark S., Connolly T. and Whittaker J. (eds), Blake 2.0, London: Palgrave Macmillan, pp. 175-86.

(2013), ‘A darker magic: Heterocosms and bricolage in Moore's recent reworkings of Lovecraft', in Matthew Green (ed.), Alan Moore and the Gothic Tradition, Manchester: Manchester University Press, pp. 253-75.

Groensteen, Thierry (2007), The System of Comics (trans. Bart Beaty and Nick Nguyen), Jackson, MS: University Press of Mississippi.

(2013), Comics and Narration (trans. Ann Miller), Jackson, MS: University Press of Mississippi.

Harms, Daniel and Gonce, John Wisdom III (2003), The Necronomicon Files: The Truth Behind the Legend, rev. ed., Boston, MA: Weiser Books.

Hutcheon, Linda (2006), A Theory of Adaptation, London: Routledge. 
Jones, Matthew T. (2005), 'Reflexivity in comic art', International Journal of Comic Art, 7:1, Spring-Summer, pp. 270-86.

Joseph, Michael (2012), 'Seeing the visible book: How graphic novels resist reading', Children's Literature Association Quarterly, 37:4, Winter, pp. 454-67.

Kidder, Orion (2010), 'Useful play: Historicization in Alan Moore’s Supreme and Warren Ellis/John Cassaday's Planetary', Journal of the Fantastic in the Arts, 21:1, pp. 77-96.

Kirshenblatt, Matthew (2017), 'Watching a serial of strange aeons: Alan Moore and Jacen Burrows' Providence', Sequart, 23 January, http://sequart.org/magazine/65691/watching-a-serial-ofstrange-aeons-alan-moore-and-jacen-burrows'-providence/. Accessed 23 October 2017.

Kristeva, Julia (1981), Desire in Language: A Semiotic Approach to Literature and Art (ed. Leon S Roudiez; trans. Thomas Gora, Alice Jardine and Leon S Roudiez), Oxford: Blackwell.

Kleiner, Rheinhart (1944), 'Bards and bibliophiles', Aonian, 2:4, Winter, pp. 169-74.

Lovecraft, Howard P. and Conover, Willis (1975), Lovecraft at Last, Arlington, VA: Carrollton, Clark.

McHale, Brian (1987), Postmodernist Fiction, London: Methuen.

Moore, Alan (2010), “"Fossil Angels”, posted by Glycon', Livejournal, 20 October, http://glycon.livejournal.com/13888.html. Accessed 23 October 2017. 
(2014), 'Introduction', in Leslie Klinger (ed.), The New Annotated H.P. Lovecraft, London:

W.W. Norton, pp. xi-xiv.

(2016), 'Crash course for the Ravers', Peasants with Pens, \#1, 10 May .

Moore, Alan and Andrade, Gabriel (2015), Crossed + One Hundred, \#4, March, Rantoul, IL: Avatar Press.

Moore, Alan and Burrows, Jacen (2011), Neonomicon, Rantoul, IL: Avatar Press.

(2015a), Providence, \#1, May, Rantoul, IL: Avatar Press.

(2015b), Providence, \#2, June, Rantoul, IL: Avatar Press.

(2015c), Providence, \#3, July, Rantoul, IL: Avatar Press.

(2015d), Providence, \#4, August, Rantoul, IL: Avatar Press.

(2015e), Providence, \#5, September, Rantoul, IL: Avatar Press.

(2015f), Providence, \#6, October, Rantoul, IL: Avatar Press.

(2016a), Providence, \#7, January, Rantoul, IL: Avatar Press.

(2016b), Providence, \#8, March, Rantoul, IL: Avatar Press.

(2016c), Providence, \#9, Weird Pulp Cover, May, Rantoul, IL: Avatar Press. 
(2016d), Providence, \#10, July, Rantoul, IL: Avatar Press.

(2016e), Providence, \#11, November, Rantoul, IL: Avatar Press.

(2017), Providence, \#12, March, Rantoul, IL: Avatar Press.

Moore, Alan and Coulthart, John (1999), 'The great old ones', in John Coulthart (ed), H.P. Lovecraft's The Haunter of the Dark and other Grotesque Visions, Telford: Creation Oneiros, n.p. (rpt. 2006).

Moore, Alan and Gibbons, Dave (1986-1987), Watchmen, \#1-\#12, New York, DC Comics.

Moore, Alan and Green, Matthew J. A. (2011), personal interview, 25 January. (2016), personal interview, 5 July.

Moore, Alan and Williams, J. H. III (2004), Promethea, \#31, August, La Jolla, CA: America’s Best Comics.

Moore, Alan, Burrows, Jacen and Johnston, Antony (2009), Alan Moore's The Courtyard, Rantoul, IL: Avatar Press.

Moore, Alan, Doane, Alan David, Johnston, Antony, Semeiks, Val, Talbot, Bryan, Zarate, Oscar (2007), Alan Moore's Yuggoth Cultures and Other Growths, Rantoul, IL: Avatar Press. 
Murray, Christopher (2013), “"These are not our promised resurrections”: Unearthing the unanny in Alan Moore's A Small Killing, From Hell, and A Disease of Language', in Matthew J. A. Green (ed.), Alan Moore and the Gothic Tradition, Manchester: Manchester University Press, pp. 215-34.

Preston, Alex (2015), 'The war against humanities and Britain's universities', The Observer, 29 March, https://www.theguardian.com/education/2015/mar/29/war-against-humanities-atbritains-universities. Accessed 3 December 2017..

Redigolo, Tim (2017), 'Alan Moore rails against plan to shut down libraries that "made” him', iNews, 20 October, https://inews.co.uk/news/uk/alan-moore-rails-plan-shut-libraries-made/. Accessed 3 December 2017.

Round, Julia (2014), Gothic in Comics and Graphic Novels: A Critical Approach, Jefferson: McFarland.

Roussi, Antoaneta (2017), 'University funding under threat from Trump tax reform', *Research Professional, 26 October, https://www.researchprofessional.com/0/rr/news/usa/congress/2017/10/University-fundingunder-threat-from-Trump-tax-reform.html. Accessed 3 December 2017.

Williams, Raymond ([1980] 2005), Culture and Materialism, London: Verso.

\section{Contributor details}

Matthew Green is an associate professor of English at the University of Nottingham. He is currently completing a monograph on Alan Moore and has additional research interests in Graphic Medicine. Previously, Matthew has published a number of journal articles, 
chapters and books on topics including William Blake, Lord Byron, Alan Moore and the Gothic. He also co-edits a speculative/weird fiction zine, Beyond Worlds, and is also a founding member of Nottingham Does Comics: http://nottinghamdoescomics.co.uk.

\section{Notes}

${ }^{1}$ Carcosa speaks with a lisp resulting from the fact that his mouth is an inhuman orifice; thus, the first line quoted would be rendered in standard speech as 'Existence is a single step from the sublime'.

${ }^{2}$ Thirteen of the 32 pages in this issue deviate from the standard four-panel horizontal grid structure as compared with an average of 5.18 deviant pages in the remaining eleven issues. The only other issue that comes close is Issue 2, which presents the first foray into an alternate world and has twelve pages that deviate from the standard grid. Issue 4 has the next greatest number of deviations with seven pages and Issues 3 and 11 have the fewest number of deviations with pages pages each. Excluding Issues 2 and 12, the average per issue number of deviant pages is 4.5 .

${ }^{3}$ In their forward, Breaty and Nguyen provide a helpful gloss to 'arthrology' (Groensteen 2007: viii-ix): 'a neologism from the Greek arthon (articulation) which deals with the study of the relations between panels, whether linear (restricted arthrology) or distant (general arthrology)'. 'Tele-arthrology' thus emphasizes the sense of communication at a distance contained in general arthrology.

4 'Yuggoth Cultures' was the working title for an episodic novel, inspired by 'Fungi from Yuggoth', that Moore shelved after losing a significant amount of the material in a taxi. Two extant stories were eventually published in a collection by Avatar Press, also named 
Yuggoth Cultures. A third story went on to become The Courtyard (Moore et al. 2009), thus inaugurating the heterocosm of which Providence is a part. 
